\title{
Implementation of three level H-bridge cascaded multilevel inverter by using AVR microcontroller for SPWM technique
}

\author{
Shivpal R. Verma", Ankita S Pande, Prashant A. Meshram, Priya P. Gaikwad, Parag G. Shewane \\ and Nitin P. Choudhary \\ Department of Electrical Engineering, DBACER, Nagpur, Maharashtra, India
}

\section{(C2017 ACCENTS}

\begin{abstract}
The multilevel inverters are basically classified as diode clamped, flying capacitor inverter and cascaded multi-level inverter. The cascaded multilevel control method is comparatively easy to other multilevel inverter because cascaded multilevel inverter do not require any clamping diode and flying capacitor. The simulation had been carried for three level cascaded H-bridge multilevel inverter (MLI) by using DC power source with advance control pulses. The main objective of this paper was to analyze three level H-bridges MLI for gate pulses generated by AVR microcontroller which reduces total harmonic distortion and enhances output voltage without adding any complexity to the power circuit and control circuit. Gating signals for these insulated-gate bipolar transistors (IGBTs) have been generated by using AVR microcontroller. In order to maintain the different voltage levels at appropriate intervals, the conduction time intervals of IGBTs have been maintained by controlling the pulse width of gating pulses.
\end{abstract}

Keywords

MLI, SPWM, $\mu C$, H-bridge.

\section{Introduction}

Inverters are the circuits which convert the DC power into AC power at essential output voltage and frequency with the use of power electronic devices. In case of normal inverters output contains only two level $+\mathrm{Vdc} \&-\mathrm{Vdc}$, the output of this inverter is not pure sine wave its output contains more harmonics. For these harmonic minimization requires additional filter circuit therefore the system makes more costly and bulky. Demerits of inverter are less efficiency, high THD, and high switching losses. To overcome these demerits, we are going to use multilevel inverter (MLI). The term Multilevel starts from threelevel converter. In 1975 the concept of multilevel converters were introduced. The first proposal for cascaded multilevel inverter was in 1975 [1]. MLI are used for high power and high voltage applications from past few years. Staircase output waveform is achieved in the output voltage of MLI, this output waveform is nearer to sinusoidal waveform. It was observed that conventional two level inverter output voltages were having more number of harmonics when compared to MLI output voltage.

*Author for correspondence

37
The reduction in harmonics with use of MLI is achieved by increasing the number of levels, generally the number of levels of output is denoted by symbol ' $N$ '. There are various control strategies to implement MLI but most widely used strategies in which its classified is Diode clamped, Flying capacitor inverter and cascaded multilevel inverter. In comparison with these techniques cascaded H-bridge MLI are easy to implement as compared to others, as it doesn't require any clamping diodes \& flying capacitors [2].

The Sinusoidal Pulse Width Modulation (SPWM) methods are mainly used in multilevel inverter control strategy. This method is most effective method for reduction of harmonics. The generation of SPWM pulses using analog technique is complicated $\&$ tedious, whereas generation of SPWM pulses using microcontroller is simpler, easy to implement and most of the task is completed in software part which reduces the hardware cost of the MLI system. For the generation of SPWM pulses AVR microcontroller $(\mu \mathrm{C})$ ATmega 32A has been used.

\section{H-bridge cascaded multilevel inverter}

The cascaded multilevel inverter has multiple units of single phase full bridge inverters connected in cascade. As we increase the number of units 
connected in cascade the number of levels of output also increases. The advantage of using multiple units in cascade is that we can synthesize desired single output from various dc sources such as batteries, fuel cells, solar PV panels etc. The ac output of each single unit is connected in series. Due to simple cascaded connections of multiple units the cascaded inverter is free from voltage clamping diodes or voltage balancing capacitors.

A cascaded MLI, as shown in Figurel is basically a series connection of several $\mathrm{H}$-bridge inverters as per the required level of output voltages. The output appearing across the load is combined output of all the bridges which are cascaded. Each single unit of full bridge inverter has its own DC source, originating from conventional or unconventional DC sources. The power circuit of Single Phase Unipolar inverter consists of four bidirectional IGBT arranged in bridge form. The circuit diagram of the power circuit is shown in Figure 1. The circuit diagram consists of four distinct IGBTs such that they are connected as the bridge circuit. The input to the circuit is the DC supply.

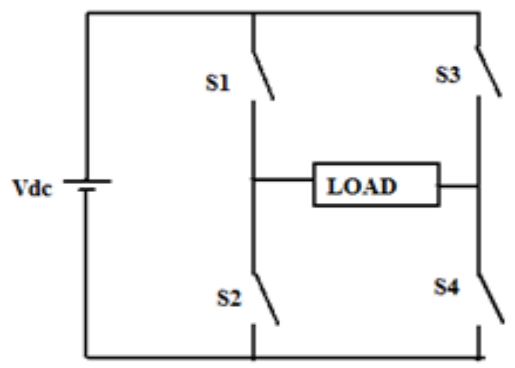

Figure 1 Cascaded H-bridge 3 level MLI

The IGBTs are triggered accordingly such that the AC output voltage is obtained at the output. The operation of the circuit is as follows

Table 1 Switching strategy for three level inverter

\begin{tabular}{cccl}
\hline Switches & + VDC & 0 & \multicolumn{1}{c}{- VDC } \\
\hline S1 & ON & OFF & OFF \\
S4 & ON & ON & OFF \\
S2 & OFF & ON & ON \\
S3 & OFF & OFF & ON \\
\hline
\end{tabular}

\section{SPWM generation using AVR microcontroller}

The gate pulses are generated by utilizing the simplicity of multi carrier sine PWM. For this procedure sine wave is the reference wave of amplitude $A_{\text {ref }}$ and frequency $F_{\text {ref }}$ which is continuously compared with triangular carrier wave of amplitude Ac and frequency fc. If sine wave is greater than triangular wave, the IGBTs are turned on otherwise off. For N level N-1 carrier wave with same frequency fc and same amplitude Ac are disposed such that the bands they occupy are contiguous. The reference waveform has peak-topeak amplitude Ar, the frequency fr and it is zero centered in the middle of the carrier set. The reference is continuously compared with each of the carrier signals. If the reference is greater than a carrier signal, then the device corresponding to that carrier is switched on otherwise off [3].

The ratio of reference amplitude (Ar) to carrier amplitude (Ac) is called as the amplitude modulation index, for implementation of pulses in MLI.

$M a=A r /(N-1) A c$

For generation of SPWM pulses with switching sequence mentioned in Table 1 AVR ATmega $32 \mu \mathrm{C}$ has been used [4]. This $\mu \mathrm{C}$ has many features like inbuilt $\mathrm{ADC}$, timer/Counter, and etc. Among all the feature, its timer/counter contains 4 PWM channels which we can utilize for generation of SPWM pulses [5-12]. The timer contains three modes which are as follows:

1. Timer 0

2. Timer 1

3. Timer 2

Among these three timer we are going to use timer 1 for generation of gate pulses. AVR has three PWM modes [13]

1. Fast PWM mode.

2. Phase correct PWM mode.

3. Phase and Frequency correct PWM mode.

In fast PWM mode the triangular wave generated is of sawtooth type while in phase correct PWM mode and phase and frequency correct PWM mode the triangular wave is of symmetrical type[8][9][11].

Algorithm for generation of SPWM pulses

Step 1: initialize variable i, duty and duty1.

Step 2: initialize array of data in sin table.

Step 3: set port D as output.

Step 4: Load TCCR1A with 0xA0 for non-inverting mode operation of compare match

Step 5: Load TCCR1B with 0x12 for Phase \& Frequency Correct PWM mode and sets the prescale to 8 .

Step 6: Set the top value in ICR1 reg.

Step 7: Load OCR1A with the count from sin table whenever TCNT1 reaches zero.

The Figure 2 below shows the SPWM pulses generated using AVR by above algorithm. 


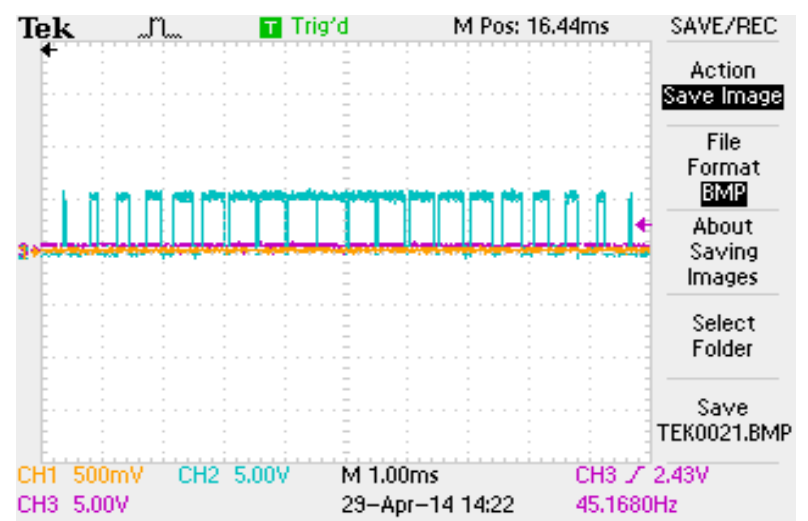

Figure 2 SPWM pulses using AVR microcontroller

\section{Simulation and hardware results}

The simulation model for three level H-bridge Cascaded MLI was developed in MATLAB as per circuit diagram shown in Figure 3. The simulation parameter used are given below in Table 2 [10][12].

Table 2 Simulation parameter

\begin{tabular}{ll}
\hline Dc Bus Voltage & $100 \mathrm{~V}$ \\
\hline Carrier frequency & $1 \mathrm{kHz}$ \\
\hline Fundamental frequency & $50 \mathrm{~Hz}$ \\
\hline Load & $\mathrm{R}=10 \Omega$ \\
\hline
\end{tabular}

Simulation model is shown in Figure 3 below:

Where, CH1-Shows SPWM pulses (Amplitude =5V).

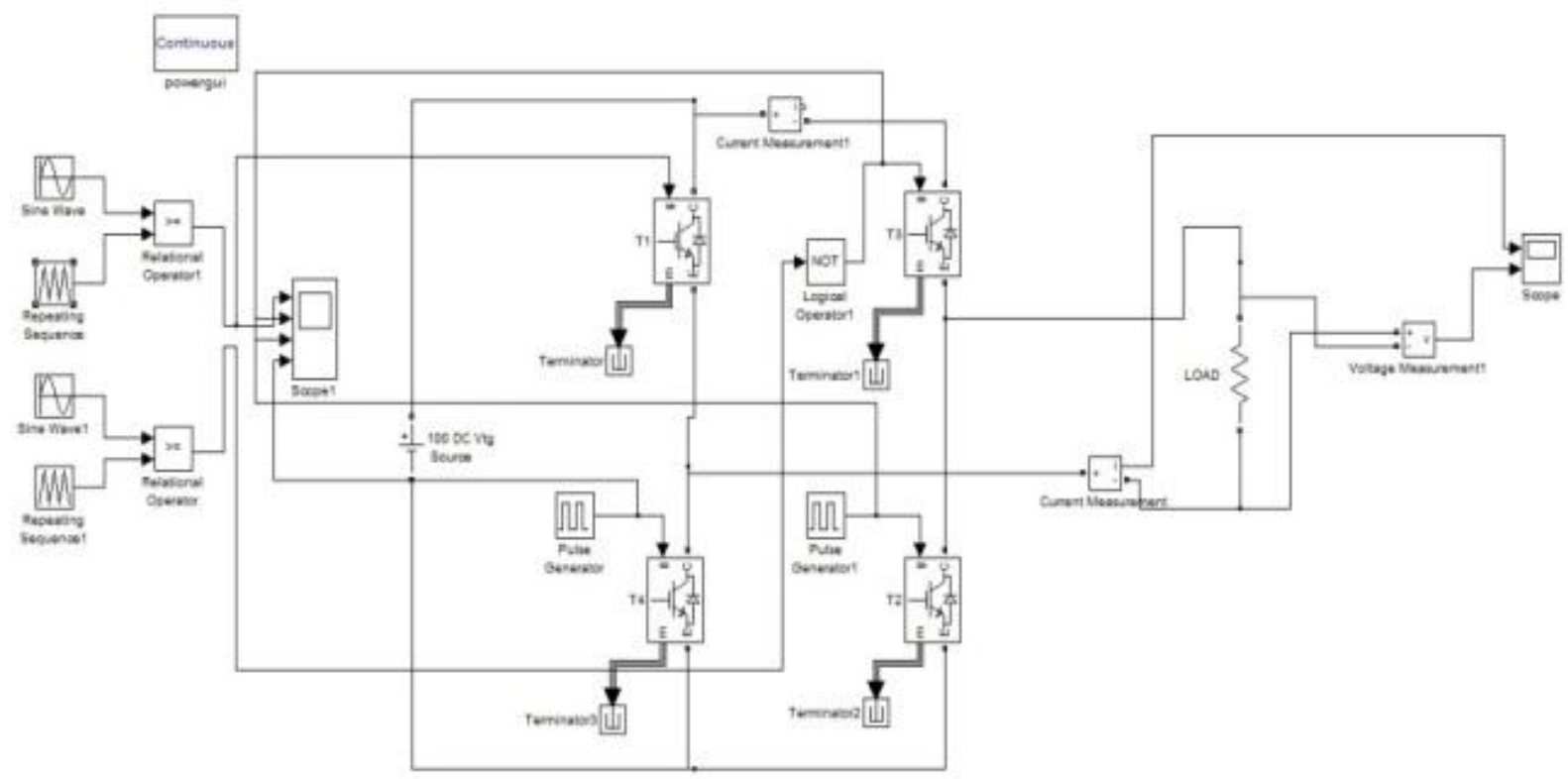

Figure 3 Simulation model for 3 level cascaded H-bridge MLI

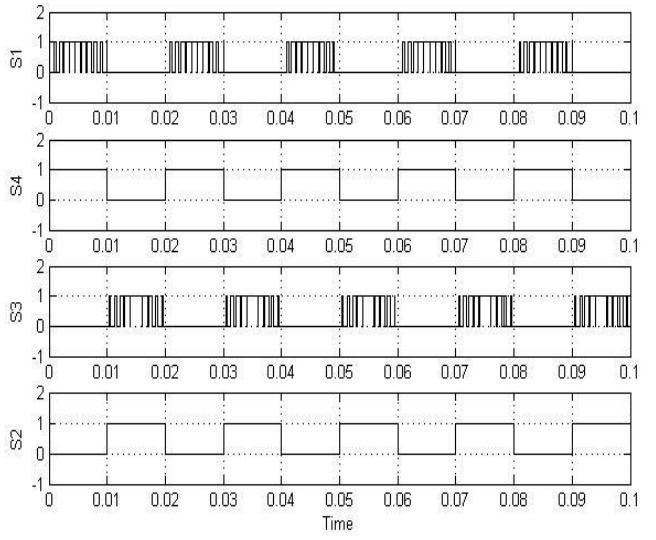

Figure 4 Gate pulses for three level H-bridges MLI
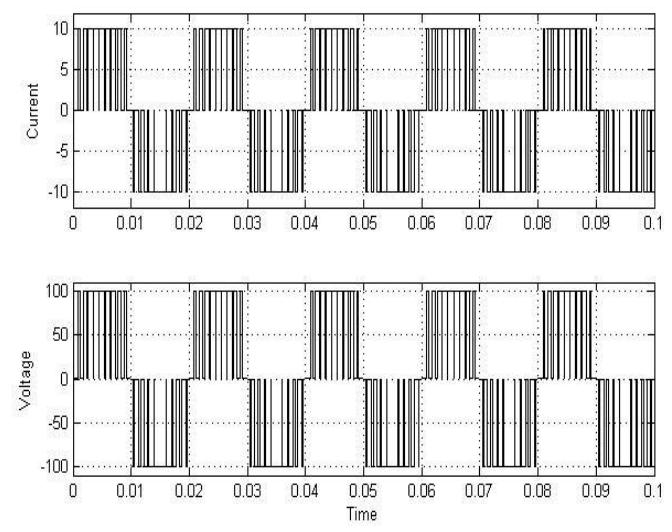

Figure 5 Phase voltage and current for H-bridge MLI 
The Figure 4 and Figure 5 show the gate pulses given to MLI and the output voltage \& current for three level H-bridges MLI. Based on simulation model the hardware was developed as shown in Figure 6 block diagram given below:

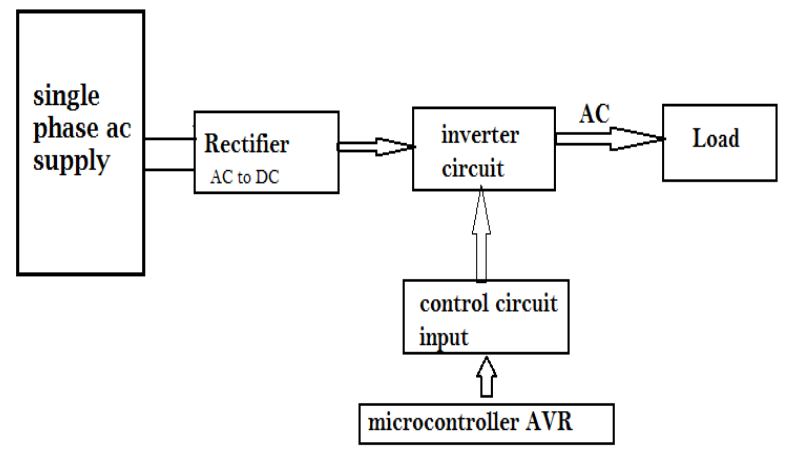

Figure 6 Block diagram for hardware implementation of 3 level H-bridge MLI

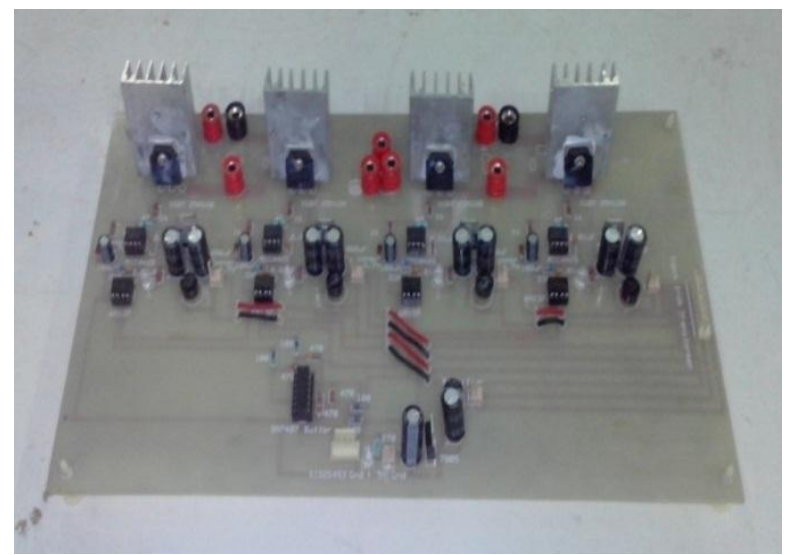

Figure 7 PCB board of power circuit and control circuit for H-bridge MLI

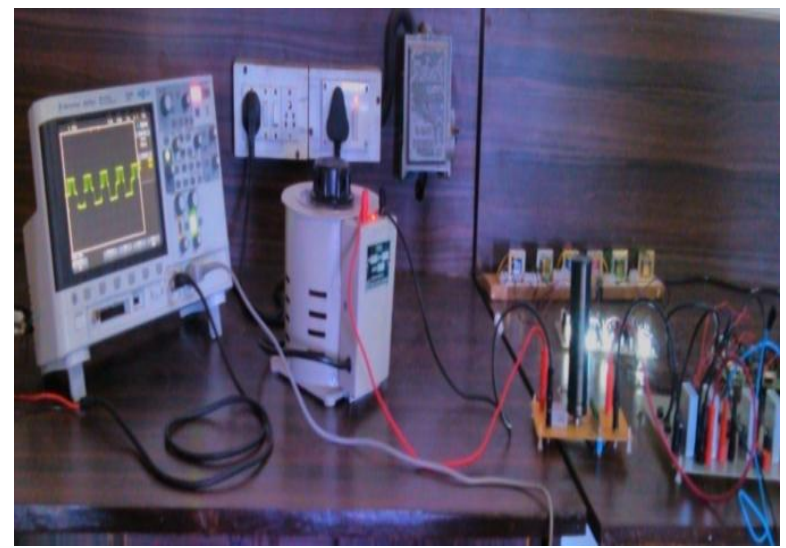

Figure 8 Complete hardware setup for three level Hbridges MLI with DSO output

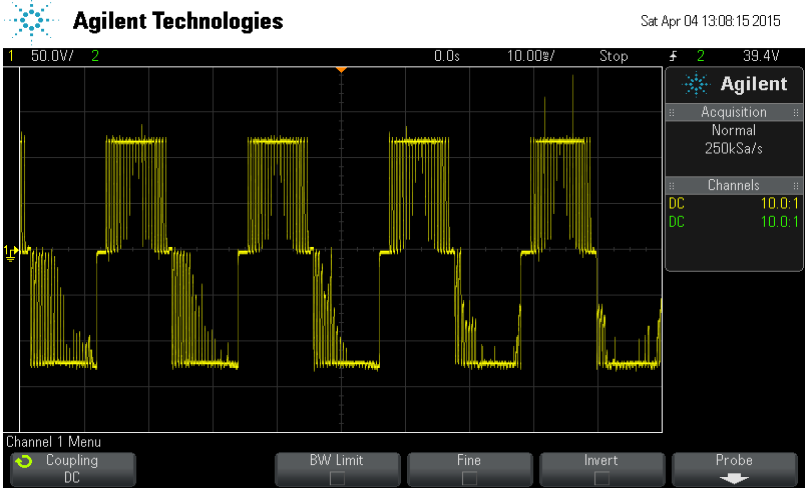

Figure 9 Output Voltage of 3 level H-bridge MLI

\section{Conclusion and future work}

Simulation of three levels Cascaded H-bridge MLI was carried out by using MATLAB/Simulink. The gate pulses have been generated by using SPWM techniques and SPWM pulses was generated by using AVR $\mu \mathrm{C}$. The implementation of hardware was done shown in Figure 6, $7 \& 8$ and three level output was achieved successfully. But there was some issue with driver circuit as shown in Figure 9 which needs to be rectified to achieve SPWM in output voltage.

\section{Acknowledgment}

None.

\section{Conflicts of interest}

The authors have no conflicts of interest to declare.

\section{References}

[1] Rodriguez J, Lai JS, Peng FZ. Multilevel inverters: a survey of topologies, controls, and applications. IEEE Transactions on Industrial Electronics. 2002; 49(4):724-38.

[2] Subramanian D, Rasheed R. Five level cascaded hbridge multilevel inverter using multicarrier pulse width modulation technique. International Journal of Engineering and Innovative Technology (IJEIT) 2013; 3(1):438-41.

[3] Iqbal A, Lamine A, Ashraf I. MATLAB/SIMULINK model of space vector PWM for three-phase voltage source inverter. In proceedings of the 41st international universities power engineering conference 2006 (1096-1100). IEEE.

[4] Baker RH, Bannister LH, inventors; Massachusetts institute of technology, assignee. Electric power converter. United States patent. 1975.

[5] Rodriguez J, Lai JS, Peng FZ. Multilevel inverters: a survey of topologies, controls, and applications. IEEE Transactions on Industrial Electronics. 2002; 49(4):724-38.

[6] Mohan D, Kurub SB. A comparative analysis of multi carrier SPWM control strategies using fifteen level 
cascaded H-bridge multilevel inverter. International Journal of Computer Applications. 2012; 41(21).

[7] Li W, Gregoire LA, Bélanger J. Control and performance of a modular multilevel converter system. In CIGRÉ conference on power systems, Canada, Halifax 2011.

[8] Venkatasubramanian D, Natarajan SP, Shanthi B. Power quality analysis for modular structured multilevel inverter with bipolar variable amplitude multicarrier pulse width modulation techniques. International Journal of Computer Applications. 2012; 49(14).

[9] Batschauer AL, Mussa SA, Heldwein ML. Threephase hybrid multilevel inverter based on half-bridge modules. IEEE Transactions on Industrial Electronics. 2012; 59(2):668-78

[10] Casadei G, Zarri L, Teodorescu R. Modular multilevel converter: modeling, simulation and control in steady state and dynamic conditions.

[11] Kavitha M, Arunkumar A, Gokulnath N, Arun S. New cascaded H-bridge multilevel inverter topology with reduced number of switches and sources. IOSR Journal of Electrical and Electronics Engineering (IOSR-JEEE). 2012; 2(6):26-36.

[12] Tolbert LM, Habetler TG. Novel multilevel inverter carrier-based PWM method. IEEE Transactions on Industry Applications. 1999; 35(5):1098-107.

[13] AVR datasheet and user manual.

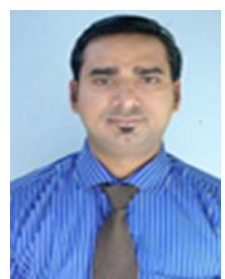

Shivpal Verma was born in Basti, India on April 24, 1988. He received his B.E (Electrical Engineering) from University of Mumbai and M.Tech (Power Electronics \& Power System) from Ramdeobaba College of Engineering \& Management, India. He is currently working as Assistant Professor in the Department of Electrical Engineering, at Dr. Babasharb Ambedkar College of Engineering and research, Nagpur, India. His research interests include Power Electronics, Control and Modeling of Converters and its application to power system and Renewable energy sources.

Email: verma.shivpal@gmail.com

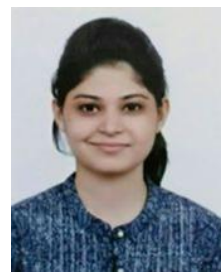

Ankita Pande was born in Arvi, India on October 23, 1989. She received his B.E (Electrical Engineering) from RTMNU and M.Tech (Power Electronics \& Power System) from Ramdeobaba College of Engineering \& Management, India. She is currently working as Assistant Professor in the Department of Electrical Engineering, at Rajiv Gandhi College of Engineering and Research, Nagpur, India. Her research interests include Power Electronics, Control and Modeling of Converters and its application to power system.

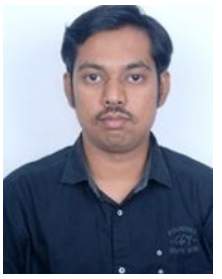

Prashant A Meshram, completed his $\mathrm{BE}$ in Electrical Engineering from RTMNU \& M.Tech in Power Electronics Power System from Ramdeobaba college of engineering \& Management, Nagpur. His key areas of research interest include power electronics converters, DC converters and applications on machines. Currently he is Assistant Professor in Department of Electrical at Dr. Babasaheb College of Engineering \& Research, Nagpur.

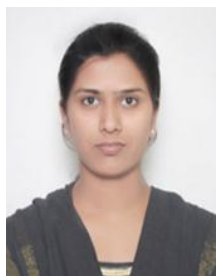

Priya Gaikwad was born in Nagpur, India on April 2, 1988. She received his B.E (Electrical Engineering) from RTMNU and M.Tech (Power Electronics \& Power System) from Ramdeobaba College of Engineering \& Management, India. She is currently working as Assistant Professor in the Department of Electrical Engineering, at Dr. Babasaheb Ambedkar College of Engineering and research, Nagpur, India. Her research interests include Power Electronics, Control and Modeling of FACTS Controller and its application to power system.

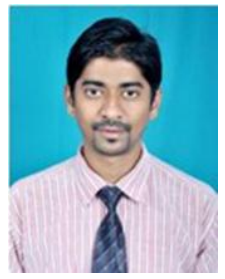

Parag Shewane, completed his BE in Electrical Engineering from RTMNU \& M.Tech in Integrated Power System from YCCE, Nagpur. His key areas of research interest include power electronics converters, power system analysis and applications on machines. Currently he is Assistant Professor in Department of Electrical at Dr. Babasaheb College of Engineering \& Research, Nagpur.

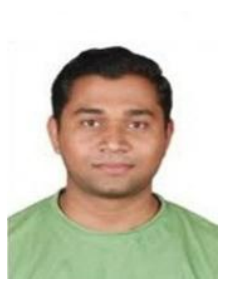

Nitin Choudhary, completed his BE in Electrical Engineering from RTMNU \& M.tech in Integrated Power System from YCCE, Nagpur. His key areas of research interest include power electronics converters, controlling of microgrid, back to back converter. Currently he is Assistant Professor in Department of Electrical at Dr. Babasaheb College of Engineering \& Research, Nagpur. 